\title{
Factor VII-401 and -402 polymorphisms and acute myocardial infarction in southern Turkey population
}

\author{
Yurdaer Dönmez ${ }^{1}$, Hasan Koca ${ }^{1} \odot$, Yahya Kemal İçen ${ }^{1} \odot$, Mustafa Demirtaş $^{2}$ \\ ${ }^{1}$ Department of Cardiology, University of Health Sciences, Adana Health Practices and Research Centre, Adana, Turkey \\ ${ }^{2}$ Department of Cardiology, Çukurova University School of Medicine, Adana, Turkey
}

DOI: $10.18621 /$ eurj.421781

\begin{abstract}
Objectives: Factor VII has a crucial role in the extrinsic coagulation pathway and initiates the thrombus formation. Some studies showed that high plasma factor VII level was related to increased acute myocardial infarction (AMI) risk. But, some studies were reported opposite findings. Some polymorphisms can change the factor VII level. There is limited information about factor VII polymorphisms in southern Turkey population. Our aim was to determine the frequencies of Factor VII-401 and -402 polymorphisms and their relation to AMI in southern Turkey area.

Methods: We enrolled 83 patients with AMI and 71 healthy subjects. Routine laboratory tests and factor VII401 and -402 polymorphisms were determined from blood samples. Factor VII -401 and -402 polymorphisms were analyzed by LightCycler device using Real-Time PCR technique.

Results: Family history of coronary artery disease and smoking frequencies were higher in patients group ( $p$ $<0.001$ and $p=0.013$, respectively). Patients had higher LDL cholesterol $(p=0.011)$ level, and lower HDL cholesterol $(p=0.025)$ level compared to healthy subjects. Factor VII-401 and -402 polymorphism genotypes were not significantly different in both groups. Also allele frequencies were similar in both groups.

Conclusion: Factor VII-401 and -402 polymorphisms do not seem to increase AMI risk in southern Turkey.
\end{abstract}

Keywords: Acute myocardial infarction, factor VII-401 and -402 polymorphisms

Received: May 7, 2018; Accepted: August 10, 2018; Published Online: January 23, 2019

In: ntracoronary thrombus is one of the reasons of acute myocardial infarction (AMI). It occurs via combination of circulating factor VII and tissue factor exposure after plaque rupture [1]. In clinical practice, it is observed that some patients with serious coronary artery disease (CAD) do not have any AMI. On the contrary, some patients without serious coronary artery lesions suffer from AMI. These facts have led the investigators to look for other abnormal thrombosis developing reasons. Some investigators focused mainly to the blood coagulation system. Increased plasma fibrinogen level was determined as a cardiovascular risk factor [2]. Factor VII is also a vitamin $\mathrm{K}$ dependent coagulation factor circulating as an inactive zymogen in blood. It has a crucial role in the extrinsic coagulation pathway and synthesized by liver [3]. There are some controversial reports in the literature about high plasma factor VII level's relation to increased AMI risk [4-7]. Factor VII level can be altered via genetic and environmental factors [8]. Guanine to

Address for correspondence: Yurdaer Dönmez, MD., University of Health Sciences, Adana Health Practices and Research Centre, Department of Cardiology, Adana, Turkey

E-mail: yurdaerd@gmail.com, Fax:+90 3223440305 
thymine $(\mathrm{G} / \mathrm{T})$ base substitution at the -401 st position of factor VII gene's promoter leads a decreased gene transcription and lower plasma factor VII level. Guanine to adenine $(\mathrm{G} / \mathrm{A})$ base substitution at the $-402^{\text {nd }}$ position of the same area increases the gene transcription and the factor VII level. Together both polymorphisms are responsible for $18 \%$ and $28 \%$ of the variation in the plasma concentrations of total factor VII and activated factor VII molecules, respectively. Both factor VII-401 and factor VII-402 polymorphism frequencies were reported as low [9]. There is limited information about factor VII polymorphisms in general Turkish population. The aim of this study was to determine the frequencies of these polymorphisms and their relation to AMI in southern Turkey population.

\section{METHODS}

We enrolled 83 patients who admitted with AMI to our coronary intensive care unit and 71 healthy subjects. Local Ethics Committee of Çukurova University was approved the study. Written informed consent was collected from all subjects. Diagnosis of AMI was based on typical chest pain, ST segment elevation in the admission electrocardiogram, and cardiac enzyme increase criteria. All patients were recruited consecutively, and all patients had their first myocardial infarction. Control subjects were selected randomly from healthy individualswho admitted for an examination to our polyclinic unit. None of these controls had any cardiovascular and valvular diseases. All the patients and control subjects were from southern Turkey. Diabetes mellitus (DM) was considered as a risk factor for atherosclerosis development [10]. Therefore, we excluded patients with DM. All patients and controls were questioned about age, gender, hypertension, smoking, hyperlipidemia, and family history. Body mass indexes were recorded. Complete blood count, glucose, lipid levels, and renal functions were recorded from routinely taken blood samples.

\section{DNA isolation}

2 cc of K3 EDTA anticoagulated venous blood sampleswere collected from all subjects for DNA analysis. DNA samples were isolated from whole blood with the aid of MagNa Pure LC DNA Isolation
Kit I by MagNa Pure LC Automated DNA isolation instrument (Roche Applied Sciences). DNA samples were stored at $-20{ }^{\circ} \mathrm{C}$ until mutations were investigated.

\section{Real-Time PCR}

Primer and hybridization probes for the factor VII $-401 \mathrm{G} / \mathrm{T}$ and $-402 \mathrm{G} / \mathrm{A}$ polymorphisms were designed and synthesized by OlfertLandt (TibMolbiol, Germany). All polymorphism-related gene regions were amplified in $20 \mu \mathrm{l}$ PCR capillary tubes. Amplification process was established using LightCycler FastStart DNA Master Hybridization Probes (Roche Applied Science). After preparation of primers, probes and kit mixtures, $18 \mu \mathrm{l}$ of the reaction mixture and $2 \mu \mathrm{l}(\sim 40 \mathrm{ng})$ genomic DNA were added in each LightCycler capillary tube. Water was used as negative control. Capillary tubes were sealed and briefly centrifuged in a microcentrifuge and then placed into the LightCycler carousel. The PCR products were detected by using 3'- fluorescein (FLU) labelled probe and 5'- Red 640 labelled probe. When both probes hybridize in close proximity, fluorescence resonance energy transfer (FRET) occurs, producing a specific fluorescence emission of LC-Red as a result of FLU excitation. Fluorescence intensity depends on the amount of specific PCR products. Amplification was monitored on-line per cycle via LightCycler device. At the end of the amplification, LightCycler device increased the temperature and measured the fluorescence same time. Temperature / fluorescence curve (melting curve) was obtained this way and polymorphisms were determined with the analysis of this curve.

\section{Statistical Analysis}

The variables were divided into two groups as categorical and continuous. Categorical data were expressed as numbers and percentages, and compared with the chi-square test. Kolmogorov-Smirnov test was used to determine whether continuous variables had normal distribution or not. Normal distributed continuous variables were compared with the independent samples t-test. Not normal distributed variables were compared with Mann-Whitney U Test. Binominal logistic regression analysis was performed with significant variables. Independent predictors were found for AMI. Statisticalanalyses were 
Table 1. Comparison of demographic findings

\begin{tabular}{lccc}
\hline & Patients $(\mathbf{n}=\mathbf{8 3})$ & Controls $(\mathbf{n}=\mathbf{7 1})$ & $\boldsymbol{p}$ value \\
\hline Age (years) & $47.5 \pm 7.5$ & $45.6 \pm 5.7$ & 0.068 \\
Male gender, n (\%) & $46(55.4)$ & $33(46.5)$ & 0.268 \\
Systolic blood pressure (mmHg) & $119.6 \pm 17.0$ & $122.7 \pm 16.5$ & 0.284 \\
Diastolic blood pressure (mmHg) & $70.2 \pm 11.5$ & $71.4 \pm 11.2$ & 0.508 \\
Pulse (beat/minute) & $81.7 \pm 8.7$ & $80.7 \pm 8.1$ & 0.489 \\
BMI (kg/m²) & $24.5 \pm 2.1$ & $24.2 \pm 2.1$ & 0.394 \\
Smoking, n (\%) & $56(67.5)$ & $34(47.9)$ & $\mathbf{0 . 0 1 3}$ \\
Family history of CAD, n (\%) & $37(44.6)$ & $11(15.5)$ & $<\mathbf{0 . 0 0 1}$ \\
Hypertension, n (\%) & $65(78.3)$ & $56(78.9)$ & 0.933 \\
Hyperlipidemia, n (\%) & $38(45.8)$ & $21(29.6)$ & $\mathbf{0 . 0 3 9}$ \\
\hline
\end{tabular}

Data are shown mean \pm standard deviation or number $(\%)$. BMI $=$ Body mass index, CAD $=$ Coronary artery disease

calculated with SPSS 20.0 (SPSS Inc., Chicago, IL, United States). A $P$ value $<0.05$ was considered to be statistically significant.

\section{RESULTS}

Demographic comparison was presented in the Table 1 . Family history of CAD $(p<0.001)$, smoking $(p=0.013)$, and hyperlipidemia $(p=0.039)$ were significantly higher in patient group $(p<0.05)$. All other variables were similar between two groups. Low density lipoprotein cholesterol (LDL-C) levels were higher $(p=0.011)$ and high density lipoprotein cholesterol (HDL-C) levels were lower $(p=0.025)$ in patient group $(p<0.05)$. Other laboratory parameters were similar (Table 2). Factor VII-401 and -402 polymorphism genotype frequencies were similar between two groups (Table 3). It was determined that both polymorphisms were suitable to the HardyWeinberg equation. Factor VII-401 G/T allele frequencies were $0.59 / 0.41$ and $0.51 / 0.49$ in patients

Table 2. Comparison of laboratory findings

\begin{tabular}{lccc}
\hline & Patients $(\mathbf{n}=\mathbf{8 3})$ & Controls $(\mathbf{n}=\mathbf{7 1})$ & $\boldsymbol{p}$ value \\
\hline Glucose $(\mathrm{mg} / \mathrm{dl})$ & $123.2 \pm 82.5$ & $100.7 \pm 7.0$ & 0.723 \\
$\mathrm{WBC}(\mathrm{uL})$ & $7.1 \pm 1.5$ & $6.8 \pm 1.8$ & 0.261 \\
$\mathrm{Hb}(\mathrm{mg} / \mathrm{dl})$ & $12.1 \pm 1.3$ & $12.1 \pm 1.5$ & 0.979 \\
$\mathrm{BUN}(\mathrm{mg} / \mathrm{dL})$ & $41.8 \pm 4.6$ & $41.1 \pm 4.5$ & 0.492 \\
$\mathrm{Cr}(\mathrm{mg} / \mathrm{dL})$ & $0.9 \pm 0.2$ & $0.9 \pm 0.1$ & 0.95 \\
$\mathrm{Na}(\mathrm{mmol} / \mathrm{L})$ & $137.7 \pm 2.6$ & $137.8 \pm 3.6$ & 0.94 \\
$\mathrm{~K}(\mathrm{mmol} / \mathrm{L})$ & $4.1 \pm 0.3$ & $4.1 \pm 0.1$ & 0.992 \\
$\mathrm{LDL}-\mathrm{C}(\mathrm{mg} / \mathrm{dl})$ & $128.7 \pm 39.2$ & $113.5 \pm 31.3$ & $\mathbf{0 . 0 1 1}$ \\
$\mathrm{HDL}-\mathrm{C}(\mathrm{mg} / \mathrm{dl})$ & $41.5 \pm 8.7$ & $44.9 \pm 9.1$ & $\mathbf{0 . 0 2 5}$ \\
Triglyceride $(\mathrm{mg} / \mathrm{dl})$ & $191.9 \pm 102.8$ & $183.5 \pm 137.7$ & 0.675 \\
Total cholesterol (mg/dl) & $202.0 \pm 47.0$ & $194.6 \pm 35.4$ & 0.284 \\
\hline
\end{tabular}

Data are shown mean \pm standard deviation. $\mathrm{WBC}=$ White blood cells, $\mathrm{Hb}=$ Hemoglobin, $\mathrm{BUN}=$ Blood urea nitrogen, $\mathrm{Cr}=$ Creatinine, LDL-C $=$ Low density lipoprotein cholesterol, HDL-C: High density lipoprotein cholesterol 
Table 3. Genotype distributions of patients and control subjects

\begin{tabular}{cccc}
\hline & Patients $(\mathbf{n}=\mathbf{8 3})$ & Controls $(\mathbf{n}=\mathbf{7 1})$ & $\boldsymbol{p}$ value \\
\hline Factor VII -401 G/T & & & \\
Homozygous G, n (\%) & $33(39.8)$ & $24(33.8)$ & 0.324 \\
Heterozygous, n (\%) & $32(38.6)$ & $24(33.8)$ & \\
Homozygous T, n (\%) & $18(21.7)$ & $23(32.4)$ & \\
Factor VII -402 G/A & & & 0.318 \\
Homozygous G, n (\%) & $38(45.8)$ & $28(39.4)$ & \\
Heterozygous, n (\%) & $25(30.1)$ & $18(25.4)$ & \\
Homozygous A, n (\%) & $20(24.1)$ & $25(35.2)$ & 0.3 \\
Allele distributions & & & 0.31 \\
Factor VII -401 G/T, n & $0.59 / 0.41$ & $0.51 / 0.49$ & \\
Factor VII -402 G/A, n & $0.61 / 0.39$ & $0.52 / 0.48$ & \\
\hline
\end{tabular}

and controls, respectively. Factor VII-402 G/A allele frequencies were $0.61 / 0.39$ in patients and $0.52 / 0.48$ in control subjects. Both groups had similar allele frequencies (Table 3). Binominal logistic regression analysis was performed with statistically significant variables. Family history of CAD (OR: 5.101, 95\%
CI: $2.200-11.825, p<0.001)$, LDL-C (OR: 1.018, 95\% CI: $1.006-1.031, p=0.003)$, and HDL-C (OR: $0.938,95 \%$ CI: $0.896-0.982, p=0.006)$ were determined as independent predictors for AMI (Table 4).

Table 4. Independent predictors for acute myocardial infarction

\begin{tabular}{lccc}
\hline & Odds ratio & CI (95\%) & $\boldsymbol{p}$ \\
\hline Family history of CAD & 5.101 & $2.200-11.825$ & $<\mathbf{0 . 0 0 1}$ \\
Hyperlipidemia & 1.182 & $0.472-2.958$ & 0.722 \\
Smoking & 0.553 & $0.248-1.229$ & 0.146 \\
LDL-C & 1.018 & $1.006-1.031$ & $\mathbf{0 . 0 0 3}$ \\
HDL-C & 0.938 & $0.896-0.982$ & $\mathbf{0 . 0 0 6}$ \\
\hline
\end{tabular}

$\mathrm{CAD}=$ Coronary artery disease, $\mathrm{LDL}-\mathrm{C}=$ Low density lipoprotein cholesterol, HDL-C = High density lipoprotein cholesterol

\section{DISCUSSION}

The main finding of our study was that this was the first study which investigated the relation between factor VII-401 and -402 polymorphisms and AMI in factor VII southern Turkey population. Classic CAD risk factors were significantly higher in patients. There was no association between these polymorphisms and AMI in this population.

It was thought that increased plasma factor VII levelcould affect the formation speed and growth of thrombus. These facts can play an important role in acute coronary syndromes. The studies whichaimed to investigate this hypothesis had controversial results in factor VII the literature [11].

Seven factor VII gene related polymorphisms have been identified. These are $\mathrm{A} / \mathrm{G}$ base substitution at the 353rd codon in exon 8 , hyper variable region 4 (HVR4) polymorphism of intron 7, decanucleotide insertion at positions $-323,-401 \mathrm{G} / \mathrm{T},-402 \mathrm{G} / \mathrm{A}$, $59 \mathrm{~T} / \mathrm{G}$, and $-32 \mathrm{~A} / \mathrm{C}[12]$.

There were conflicting results in studies that 
investigated the relation between CAD and first two polymorphisms [13-16]. It was reported that -323rd nucleotide polymorphism in promoter has no biological activity [9]. Effects of the $-401 \mathrm{G} / \mathrm{T}$ and 402 G/A polymorphisms over CAD and cerebrovascular diseasewere investigated in limited number of studies [17-20].

Kang et al. [17] reported that activated factor VII (FVIIa) level and factor VII coagulant activity (FVIIc) were higher in the AMI patients. But, CAD patients without AMI had similar FVIIa, FVIIc, and factor VII antigen (FVIIag) levels compared to control subjects. Their study population consisted of 60 CAD patients (33 of these patients had AMI) and 149 control subjects. Factor VII-401 and -402 polymorphism genotype and allele distributions were not different between groups. Same investigators showed that FVIIa, FVIIc, and FVIIag levels were higher in 62 cerebral infarction patients compared to the 149 healthy subjects [18]. They also reported that polymorphism genotype and allele distributions were similar in both groups.

Evangelista et al. [19] investigated the effect of factor VII-401 and -402 polymorphisms in arterial and venous thrombotic events. Their patient group consisted of 104 participants and control group had 106 healthy subjects. They showed that there was no significant difference about these polymorphisms between patients and controls. Likewise, Ramzi et al. [20] reported a similar result in their study. They tried to identify the role of factor VII-401 G/T and HVR4 polymorphisms in CAD. They enrolled 110 patients and 110 control subjects. They found no association between these polymorphisms and CAD. There were no genotype distribution and allele frequency difference between our groups. Our results were compatible with these studies.

Allele distributions can vary significantly in different populations. Kang et al. [17] found allele frequencies $0.03 / 0.97$ for factor VII-401 G/T and $0.48 / 0.52$ for $-402 \mathrm{G} / \mathrm{A}$ in patients. We found $-401 \mathrm{G} / \mathrm{T}$ allele frequency $0.59 / 0.41$ and $-402 \mathrm{G} / \mathrm{A}$ allele frequency $0.61 / 0.39$ in our patient group. Van't Hooft et al. [9] found $-401 \mathrm{G} / \mathrm{T}$ and $-402 \mathrm{G} / \mathrm{A}$ allele frequency $0.91 / 0.09$ and $0.71 / 0.29$ respectively in healthy European subjects. Kang et al. [17] found allele frequencies for $-401 \mathrm{G} / \mathrm{T}$ and $-402 \mathrm{G} / \mathrm{A}$ polymorphisms in healthy Chinese subjects $0.97 / 0.03$ and $0.52 / 0.48$, respectively. In our control group, -401 $\mathrm{G} / \mathrm{T}$ allele frequency was $0.51 / 0.49$ and $-402 \mathrm{G} / \mathrm{A}$ allele frequency was $0.52 / 0.48$. There was a noticeable difference in the factor VII-401 G/T allele frequency between our population and their populations.

\section{Limitations}

Factor VII-401 and -402 polymorphism's effects on the factor VII level have been identified before. Some of the studies did not include measurements of factor VII [21]. We also did not measure factor VII level for this reason. But, this is an important limitation for us. Also, our small sample size is another limitation.

Age, lipid levels, obesity, andsmoking can alter factor VII level [22]. When all the environmental and genetic risk factors taken into account, we still have limited information about which factor how much strongly affects factor VII level. Further studies are needed to clarify role of factor VII gene polymorphism over arterial thrombosis development.

\section{CONCLUSION}

There is an association between classic CAD risk factors and AMI, butfactor VII-401 and -402 polymorphisms do not seem to increase risk of AMI in southern Turkey population.

\section{Conflict of interest}

The authors disclosed no conflict of interest during the preparation or publication of this manuscript.

\section{Financing}

The authors disclosed that they did not receive any grant during conduction or writing of this study.

\section{Acknowledgements}

The authors want to thank Mr. Kahraman Tanriverdi for his valuable contributions.

\section{REFERENCES}

[1] Rao LV, Rapaport SI. Activation of factor VII bound to tissue factor: a key early step in the tissue factor pathway of blood coagulation. Proc Natl Acad Sci USA 1988;85:6687-91. 
[2] Sakakibara H, Fujii C, Naito M. Plasma fibrinogen and its association with cardiovascular risk factors in apparently healthy Japanese subjects. Heart Vessels 2004;19:144-8.

[3] Broze GJ Jr, Majerus PW. Purification and properties of human coagulation factor VII. J Biol Chem 1980;255:1242-7.

[4] Meade TW, Ruddock V, Stirling Y, Chakrabarti R, Miller GJ. Fibrinolytic activity, clotting factors, and long-term incidence of ischaemic heart disease in the Northwick Park Heart Study. Lancet 1993;342:1076-9.

[5] Heinrich J, Balleisen L, Schulte H, Assmann G, van de Loo J. Fibrinogen and factor VII in the prediction of coronary risk. Results from the PROCAM study in healthy men. Arterioscler Thromb 1994;14:54-9.

[6] Heywood DM, Ossei-Gerning N, Grant PJ. Association of factor VII:C levels with environmental and genetic factors in patients with ischaemic heart disease and coronary atheroma characterised by angiography. Thromb Haemost 1996;76:161-5. [7] Folsom AR, Wu KK, Rosamond WD, Sharrett AR, Chambless LE. Prospective study of hemostatic factors and incidence of coronary heart disease: the Atherosclerosis Risk in Communities (ARIC) Study. Circulation 1997;96:1102-8.

[8] Green F, Humphries S. Genetic determinants of arterial thrombosis. Baillieres Clin Haematol 1994;7:675-92.

[9] van't Hooft FM, Silveira A, Tornvall P, Iliadou A, Ehrenborg $\mathrm{E}$, Eriksson P, et al. Two common functional polymorphisms in the promoter region of the coagulation factor VII gene determining plasma factor VII activity and mass concentration. Blood 1999;93:3432-41.

[10] Matheus AS, Tannus LR, Cobas RA, Palma CC, Negrato CA, Gomes MB. Impact of diabetes on cardiovascular disease: an update. Int J Hypertens 2013;2013:653789.

[11] Endler G, Mannhalter C. Polymorphisms in coagulation factor genes and their impact on arterial and venous thrombosis. Clin Chim Acta 2003;330:31-55.

[12] Grant PJ, Humphries SE. Genetic determinants of arterial thrombosis. Baillieres Best Pract Res Clin Haematol 1999;12:505-32.

[13] Iacoviello L, Di Castelnuovo A, de Knijff P, D'Orazio A, Amore C, Arboretti R, et al. Polymorphisms in the coagulation factor VII gene and the risk of myocardial infarction. N Engl J
Med 1998;338:79-85.

[14] Girelli D, Russo C, Ferraresi P, Olivieri O, Pinotti M, Friso $\mathrm{S}$, et al. Polymorphisms in the factor VII gene and the risk of myocardial infarction in patients with coronary artery disease. $\mathrm{N}$ Engl J Med 2000;343:774-80.

[15] Corral J, González-Conejero R, Lozano ML, Rivera J, Vicente V. Genetic polymorphisms of factor VII are not associated with arterial thrombosis. Blood Coagul Fibrinolysis 1998;9:267-72.

[16] Lane A, Green F, Scarabin PY, Nicaud V, Bara L, Humphries $\mathrm{S}$, et al. Factor VII Arg/Gln353 polymorphism determines factor VII coagulant activity in patients with myocardial infarction (MI) and control subjects in Belfast and in France but is not a strong indicator of MI risk in the ECTIM study. Atherosclerosis 1996;119:119-27.

[17] Kang WY, Wang HL, Xiong LF, Wang XF, Chu HY, Qu B, et al. Study on plasma coagulation factor VII (FVII) levels and polymorphisms of FVII gene in patients with coronary heart diseas. Zhonghua Xue Ye Xue Za Zhi 2002;23:457-9.

[18] Kang WY, Wang HL, Xiong LF, Wang XF, Chu HY, Qu B, et al. Polymorphisms of the coagulation factor VII gene and its plasma levels in relation to acute cerebral infarction differences in allelic frequencies between Chinese Han and European populations. Chin Med 2004;117:71-4.

[19] Evangelista FC, Rios DR, Ribeiro DD, Carvalho MG, Dusse LM, Fernandes AP, et al. Lack of association between potential prothrombotic genetic risk factors and arterial and venous thrombosis. Genet Mol Res 2015;14:9585-94.

[20] Ramzi M, Cohan N, Yavarian M, Jahromi MR, Beigi MB, Fakhraee F, et al. Coagulation factor VII gene polymorphisms and cardiovascular diseases in Iranian population. J Indian Coll Cardiol 2013;3:6-8.

[21] Wang XL, Wang J, McCredie RM, Wilcken DE. Polymorphisms of factor V, factor VII, and fibrinogen genes. Relevance to severity of coronary artery disease. Arterioscler Thromb Vasc Biol 1997; 17:246-51.

[22] Shimokata K, Kondo T, Ohno M, Takeshita K, Inden Y, Iino $\mathrm{S}$, et al. Effects of coagulation Factor VII polymorphisms on the coronary artery disease in Japanese: Factor VII polymorphism and coronary disease. Thromb Res 2002;105:493-8. 